\title{
Establishment and practice of land subsidence control and management system for deep foundation pit dewatering in Shanghai
}

\author{
Xinlei Huang ${ }^{1,2,3}$, Tianliang Yang ${ }^{1,2,3}$, Jianzhong $\mathrm{Wu}^{1,2,3}$, Jinxin $\operatorname{Lin}^{1,2,3}$, and $\mathrm{Ye} \mathrm{He}^{1,2,3}$ \\ ${ }^{1}$ Key Laboratory of Land Subsidence Monitoring and Prevention, Ministry of Natural Resources of China, \\ Shanghai, 200072, China \\ ${ }^{2}$ Shanghai Institute of Geological Survey, Shanghai, 200072, China \\ ${ }^{3}$ Shanghai Engineering Research Center of Land Subsidence, Shanghai, 200072, China
}

Correspondence: Xinlei Huang (huangx12009@126.com)

Published: 22 April 2020

\begin{abstract}
At present, large-scale engineering construction activities, especially deep foundation pit dewatering, are important factors of land subsidence in Shanghai, which induces uneven land subsidence. To solve this problem, this paper puts forward a technical approach to prevention and control the land subsidence. Based on the practice of joint work by multiple administrative departments in Shanghai, this paper further combines the technology and management measures effectively, and summarizes the management system of land subsidence control for deep foundation pit dewatering. Meanwhile, this paper provides the key workflow, starting from the whole process control of construction project for feasibility demonstration, design, construction and completion. The practice shows that the whole process of deep foundation pit dewatering control and management provides a powerful guarantee for land subsidence prevention and control.
\end{abstract}

\section{Introduction}

As a typical thick quaternary coverage area, the uneven land subsidence in shanghai caused by large-scale engineering construction activities, especially the deep foundation pit dewatering, has attracted attention on the background that groundwater unreasonable exploitation, ever the main inducing factors at one time, has been effectively controlled to below $5 \times 10^{6} \mathrm{t} \mathrm{yr}^{-1}$ (Yang et al., 2015; Yan et al., 2019). At present, there are few studies on the land subsidence caused by foundation pit dewatering in the world. Shanghai takes the lead in putting forward the whole process joint control and management mode of deep foundation pit dewatering. Monitoring data show that the trend of uneven land subsidence in the city has been alleviated, and the annual land subsidence has been controlled within $6 \mathrm{~mm}$ for many years in a row. This paper puts forward the technical approach, and summarizes the control system and working mechanism of land subsidence of deep foundation pit dewatering from the aspects of laws and regulations, technical standards, manage- ment mechanism, information sharing and work evaluation in Shanghai.

\section{Technical approach of land subsidence control for deep foundation pit dewatering}

Foundation soils in the main urban area of Shanghai are Quaternary sediments, which are mainly composed of clayey soil, silty soil and sandy soil, and are divided into nine engineering geological layers. Among them, 7 and 8 layers, the first confined aquifer and the second confined aquifer in hydrogeology respectively, are usually necessary to reduce the groundwater level in the process of excavation to ensure the stability of deep foundation pits.

The research shows that deep foundation pit dewatering results in the decrease of surrounding groundwater level, which leads to significant land subsidence. The radius of land subsidence funnel induced by dewatering with hanging waterproof curtain can reach 10 times greater than the depth of 


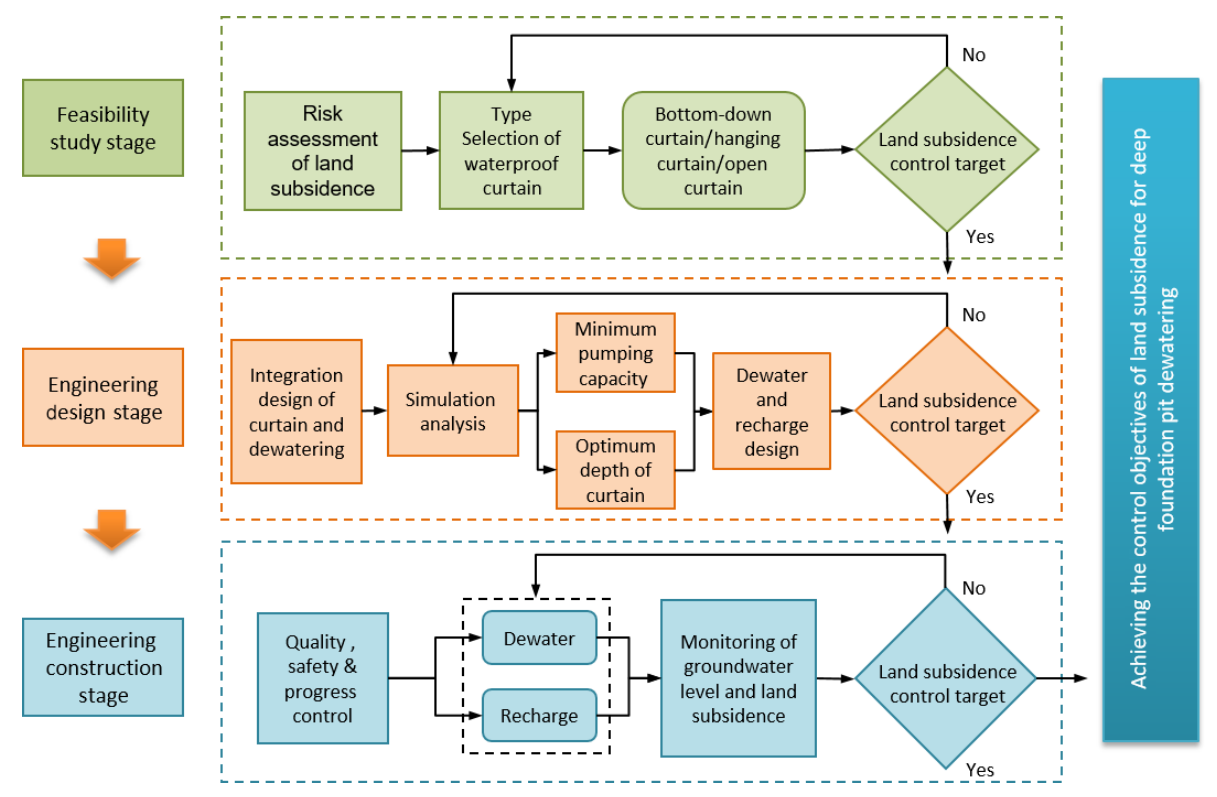

Figure 1. Technical path of land subsidence control for deep foundation pit dewatering.

foundation pit excavation (Yang et al., 2015). Because it is difficult to control and restore the ground subsidence after the occurrence, the land subsidence control of deep foundation pit dewatering should focus on the process prevention and control; therefore, based on the idea of the whole process management and control of pre-construction, in-process and post-construction, the key technology of the land subsidence prevention and control for deep foundation pit dewatering is combined with the construction process, and the technical path is proposed as shown in Fig. 1 (Huang et al., 2015; Yan, et al., 2019).

\section{Management system of land subsidence control for deep foundation pit dewatering}

Effective administrative management is a powerful guarantee to promote the implementation of various prevention and control measures, and is also the key to the effective prevention and control of land subsidence. In the past, the management and control system of construction projects mainly focused on land planning control and engineering quality safety, but paid little attention to the geological environment problems such as land subsidence. In order to control the uneven land subsidence caused by deep foundation pit dewatering, "Regulations of Shanghai Municipality on the Administration of Prevention and Control of Land Subsidence" has been promulgated. It has strengthened the joint management of relevant administrative departments, and promoted the revision and promulgation of a number of administrative regulations, technical requirements and other supporting systems. Through the workflow reengineering and practice summary, this paper puts forward the control and management system framework of land subsidence for deep foundation pit dewatering shown in Fig. 2, combining the technical measures and management measures, which has strengthened the control and management of land subsidence for deep foundation pit dewatering.

\subsection{Legal system}

Shanghai has issued a number of laws and regulations, such as Regulations of Shanghai Municipality on the Administration of Prevention and Control of Land Subsidence, Regulations of Shanghai Municipality on the Administration of Risk Assessment and Management of Geological Disasters, Regulations of Shanghai Municipality on the Administration of Management of Foundation Pit Engineering, which clarify the legal responsibilities, requirements and tasks of the relevant administrative departments. The legal system for land subsidence control of deep foundation pit dewatering has been preliminarily formed, and provides guarantee for the legalization and standardization of land subsidence prevention and control.

\subsection{Cooperation mechanism}

Shanghai has constructed a coordinated management mode to control land subsidence, that the municipal planning and resource administrative department, which is the comprehensive supervisory and administrative department for prevention and control of ground subsidence in this Municipality, joint the municipal water affairs administrative department, the municipal housing, urban and rural construction administrative department, the municipal transportation administration department and so on, formulate the annual work plan 


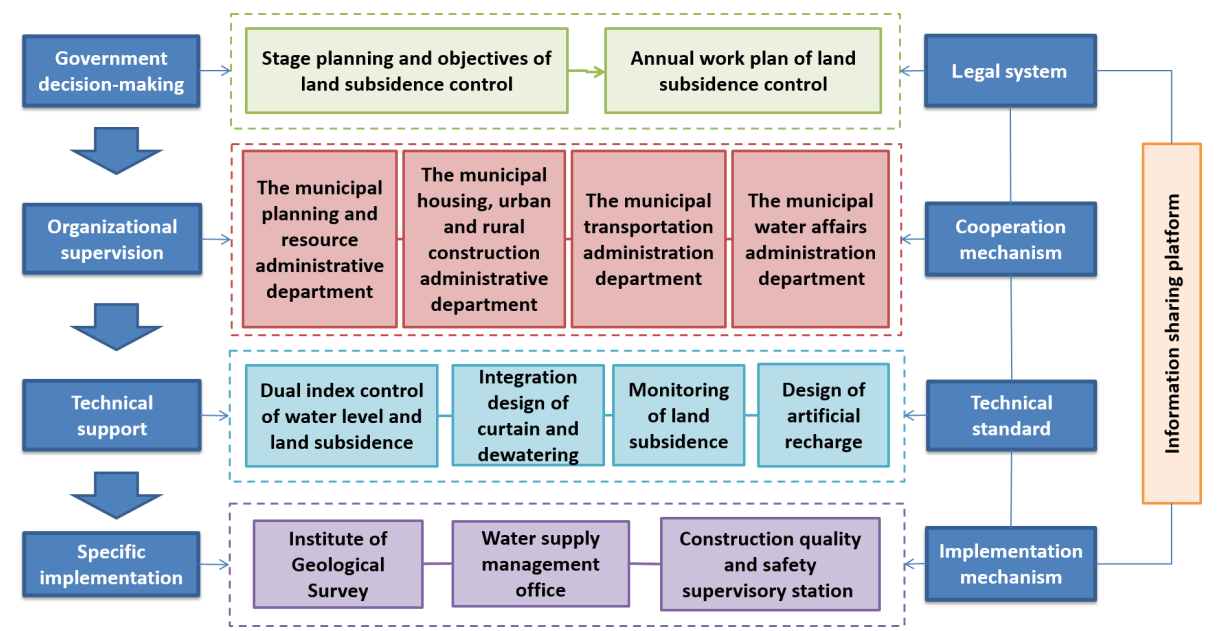

Figure 2. Management system framework of land subsidence control for deep foundation pit dewatering.

for land subsidence prevention and control under the idea of land subsidence control zoning (Wang et al., 2015). According to the control target, the whole process of deep foundation pit dewatering is coordinated control and management. Furthermore, the financial administrative department carries out tracking evaluation and performance evaluation of land subsidence prevention and control work every year, which has practical significance for promoting the standardization of daily land subsidence prevention and control work. Now the process of cross-departmental collaborative management is being actively optimized and improved.

\subsection{Technical standard}

Shanghai has formulated a series of technical specifications for land subsidence prevention and control, such as Technical Code for Land Subsidence Monitoring and Control, Technical Code for Risk Assessment of Geological Disaster, Technical Code for Integration Pumping and Recharge in Deep Foundation Pit, Technical code for Hydrogeological Investigation of Engineering, etc. It provides a unified technical standard for the whole process of feasibility study, special investigation, design and implementation of construction projects, and provides a strong technical support for the implementation of laws and regulations.

At present, standardized application of key prevention and control technologies, such as risk assessment of land subsidence, dual index control of water level and land subsidence, integrated design of curtain waterproof and dewatering, land subsidence monitoring and artificial recharge for foundation pit dewatering, is being carried out, and the revision and perfection of relevant technical standards are being promoted (Huang, 2018).

\subsection{Implementation mechanism}

The technical support units under the administrative departments, such as institute of geological survey, water supply management office, construction quality and safety supervisory station, etc., vigorously promote the study on the mechanism, characteristics, monitoring and prevention of land subsidence for deep foundation pit dewatering, and strengthen technical support for relevant administrative mechanisms and laws and policies, and continuously improve the level of prevention and control of land subsidence in deep foundation pit dewatering. Meanwhile, they regularly summarize the work of land subsidence control in the view of the technical point, put forward suggestions for prevention and control plan, provide technical consultation services for administrative departments making policy decision, and play an important role in improving the effectiveness of land subsidence prevention and control work.

\subsection{Information sharing}

The municipal planning and resource administrative department takes the lead in holding regular joint departments meetings to inform the progress, study the situation, discuss the countermeasures, deploy the tasks of land subsidence prevention and control. So that all departments can cooperate to effectively supervise the whole process of deep foundation pit dewatering.

At present, "Shanghai Foundation Pit Information Management Platform" is being constructed, which will further enhance the timeliness and convenience for data sharing in the whole process of deep foundation pit dewatering, and further improve the cross-sectoral coordination ability and work effectiveness of land subsidence control. 


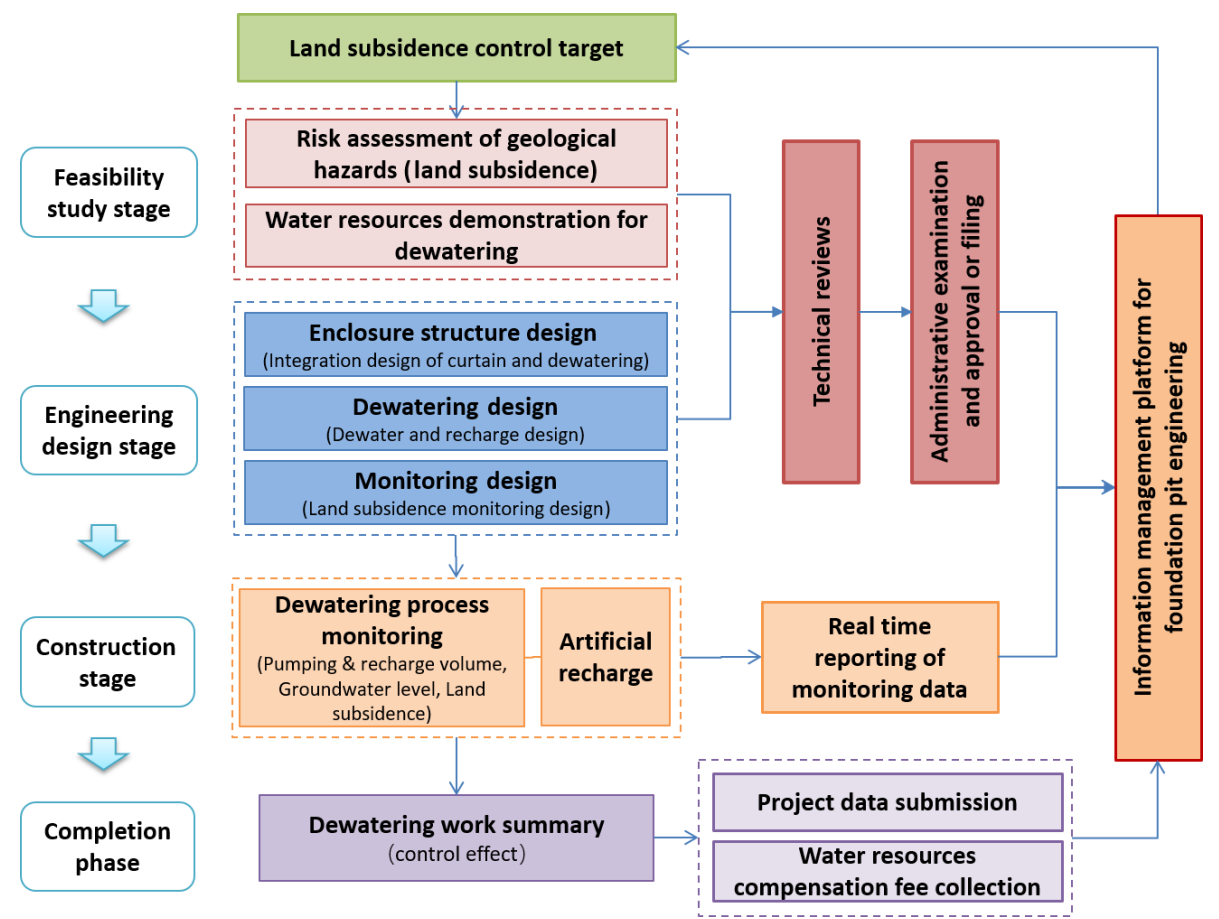

Figure 3. Key workflow of whole process management of deep foundation pit dewatering based on land subsidence control.

\section{Key work flow of land subsidence control for deep foundation pit dewatering}

Based on the land subsidence control and management system of deep foundation pit dewatering in Shanghai, this paper, combined with the technical path and the key links of engineering construction management, explores how to bring the technical measures of land subsidence control of deep foundation pit dewatering into the mainstream of construction project management from the aspects of risk assessment of geological hazards, water resources demonstration for dewatering, design, construction and completion. The key workflow of whole process coordinated management of land subsidence for deep foundation pit dewatering is summarized and formed as shown in Fig. 3. And relying on the information sharing platform of foundation pit engineering, the management measures of technical review, administrative approval, process supervision and data exchange are taken as the grasp to promote the land subsidence control measures of deep foundation pit dewatering.

\section{Conclusions}

Practice has proved that effective management is an important measure to ensure the implementation to be done and achieves the expected results of land subsidence prevention and control measures. Shanghai took the lead in summarizing the land subsidence control and management mode for deep foundation pit dewatering from the aspects of techni- cal path, control and management system and key working process, and formed the scheme of multi-sectoral collaborative management of land subsidence, which achieved the expected results. In the future, Shanghai will continue to improve the land subsidence control and management system in practice, and further enhance the fine ability and effect.

Data availability. No data, models, or code were generated or used during the study.

Author contributions. XH contributed significantly to design and wrote the manuscript, TY contributed to constructive discussions and manuscript review, JW helped perform the conception of the study, JL and YH performed analysis and manuscript preparation.

Competing interests. The authors declare that they have no conflict of interest.

Special issue statement. This article is part of the special issue "TISOLS: the Tenth International Symposium On Land Subsidence - living with subsidence". It is a result of the Tenth International Symposium on Land Subsidence, Delft, the Netherlands, 17-21 May 2021. 
Acknowledgements. This is a contribution of the IGCP-663 project "Impact, Mechanism, Monitoring of Land Subsidence in Coastal Cities" of the IUGS and UNESCO. The authors also thank their colleagues for continuing support.

Financial support. This research has been supported by the International Geoscience Programme (grant no. IGCP 663) and the Science and Technology Commission of Shanghai Municipality, China (grant nos. 12231200700 and 18DZ1201100).

\section{References}

Huang, X. L.: Design method and application research of a foundation pit enclosure and dewatering integration system for land subsidence control, Shanghai Land Resour., 39, 122-125, https://doi.org/10.3969/j.issn.2095-1329.2018.04.026, 2018.
Huang, X. L., Zhan, G. H., and Yang, T. L.: Discussion on the Key Technologies of Land Subsidence Prevention and Controlling for Deep Foundation Pit Engineering, in: Regional geological science and technology forum in eastern China, Shanghai, China November 2015, 351-355, 2015.

Wang, J. X., Liu, X. T., and Yang, T. L.: Prevention partition for land subsidence induced by engineering dewatering in Shanghai, in: Proc. IAHS/Symposium on land subsidence, Nagoya, Japan, November 2015, 207-210, 2015.

Yan, X. X., Wang, H. M., Yang, T. L., Huang, X. L., Zhan, G. H., and He, Y: Main achievements and applications of land subsidence induced by deep foundation pits dewatering in coastal area, a case study of Shanghai, Geol. Surv. China, 6, 69-76, https://doi.org/10.19388/j.zgdzdc.2019.01.10, 2019.

Yang, T. L., Yan, X. X., Wang, H. M., Huang, X. L., and Zhan, G. H.: Comprehensive experimental study on prevention of land subsidence caused by dewatering in deep foundation pit with hanging waterproof curtain, in: Proc. IAHS/Symposium on land subsidence, Nagoya, Japan, November 2015, 1-5, 2015. 